\title{
Riesgos en el cuidado de la salud de las familias de Valledupar
}

\author{
Marina Sánchez-Sanabria* \\ Javier Galindo-Ospino**
}

Recibido:

14 de Noviembre de 2015

\section{RESUMEN}

Objetivo: determinar los principales factores de riesgo que afectan la calidad de vida que asumen en el cuidado de la salud los habitantes del área urbana de Valledupar, para los estratos socioeconómicos 1, 2 y 3 de la comuna tres. Materiales y Métodos: estudio cuantitativo, descriptivo, transversal; muestra conformada por 68 de 127 familias y 31 representantes comunitarios, aplicándoseles encuesta sobre aspectos sociodemográficos, condición de vida, cuidado de la salud y lista de chequeo para condiciones higiénico sanitarias de 54 expendios de alimentos distribuidos proporcionalmente. Resultados: se identificaron como los principales factores de riesgo un $41 \%$ de formación técnica, $23 \%$ de mujeres desde temprana edad son amas de casa y formando pareja, y $8.8 \%$ embarazadas, $83.8 \%$ con insuficientes para sostenimiento, $57 \%$ de mujeres no practican autoexamen de mama en el último año, y $26.5 \%$ sin examen citológico, $76 \%$ de hombres no hacen examen de próstata, $70 \%$ de mujeres con deficiente manejo de lactancia materna exclusiva y alimentación complementaria, $50 \%$ no lleva perros al control veterinario y $69 \%$ deja hacer sus necesidades a campo abierto, $49 \%$ de expendios de alimentos no cumplen con la infraestructura, manejo higiénico sanitario y de bioseguridad. Conclusión: se aprecian comportamientos negativos en el autocuidado de la salud sexual y salud reproductiva, deficiente manejo con la lactancia materna y alimentación complementaria, con el cuidado de animales domésticos y precarias prácticas higiénico sanitarias en expendios de alimentos que deben ser reconsiderados para potenciar estilos de vida saludables.

PALABRAS CLAVE: autocuidado, conducta de riesgo, estilo de vida***

Para citar este artículo / To reference this article / Para citar este artigo

Sánchez-Sanabria M, Galindo-Ospino J. Riesgos en el cuidado de la salud de las familias de Valledupar. Rev. cienc. cuidad. 2016; 13(1): 23-42.
"Enfermera.

Doctora en

Ciencias de

la Educación.

Docente.

Universidad

Popular del

Cesar. Valledupar,

Colombia. Correo

electrónico:

marinasanchez@

unicesar.edu.co

** Enfermero.

Especialista en

Gerencia. Docente.

Universidad

Popular del

Cesar. Valledupar,

Colombia. Correo electrónico:

javiergalindo@

unicesar.edu.co

*** Descriptores en Ciencias de la Salud (DeCS), en la página http:// decs.bvs.br/E/ homepagee.htm de la Biblioteca virtual en salud del proyecto BIREME, de la Organización Mundial de la Salud y de la Organización Panamericana de la Salud. 


\section{Risks in the health care of the families of Valledupar}

\section{ABSTRACT}

Objective: to identify the main risk factors that affect the quality of life assumed in health care by the residents from the urban area of Valledupar, for the socioeconomic strata 1,2 and 3 from the third commune. Materials and Methods: quantitative, descriptive, crosssectional study; sample consisted of 68127 families and 31 community representatives; Survey administered based on sociodemographic aspects, living conditions, health care, and checklist for sanitary and hygienic conditions of 54 proportionately distributed food outlets. Results: the resuts show as the main risk factors, $41 \%$ of technical training, $23 \%$ of women from eleven years of age are housewives forming couples at an early age and $8.8 \%$ pregnant, $83.8 \%$ do not have the income to support themselves, $57 \%$ of women have not practice breast self-examination since last year and $26.5 \%$ without cytological examination, $76 \%$ of men do not have their prostate checked, $70 \%$ of women with poor exclusive maternal breast-feeding management and supplementary feeding, 50\% do not take dogs for veterinary control and $69 \%$ leave them to do their business in the open field, $49 \%$ of food establishments do not comply with the infrastructure, sanitary hygienic handling and biosafety. Conclusion: negative behaviors are seen in self care of sexual health and reproductive health, poor breast and supplementary feeding management, taking care of pets and poor hygienic and sanitation practises in food establishments, which should be reconsidered to enhance healthy lifestyles.

KEY WORDS: self-care, risk taking, lifestyle. 


\section{Riscos na saúde das famílias de Valledupar}

\section{RESUMO}

Objetivo: identificar os principais fatores de risco que afetam a qualidade de vida que assumem nos residentes de cuidados de saúde da área urbana de Valledupar, por estratos socioeconômicos 1, 2 e 3 da comuna três. Materiais e Métodos: descritiva Quantitativa, estudo, transversal; amostra foi constituída por 68127 famílias e 31 representantes da comunidade, pesquisa aplicada a eles aspectos sociodemográficos, condições de vida, saúde, e lista de verificação para as condições de saúde e higiene distribuídos proporcionalmente 54 estabelecimentos de comida. Resultados: foram identificados como os principais fatores de risco de $41 \%$ da formação técnica, $23 \%$ das mulheres desde tenra idade, são donas de casa e como um par, e $8,8 \%$ de mulheres grávidas, $83,8 \%$ com apoio insuficiente, $57 \%$ das mulheres não praticam o auto-exame da mama no ano passado, e $26,5 \%$ sem exame citológico, $76 \%$ dos homens não exame de próstata, $70 \%$ das mulheres com má gestão da amamentação exclusiva ea alimentação complementar, $50 \%$ não carregam cães de controlo veterinário e $69 \%$ deixam aliviar a campo aberto, $49 \%$ dos estabelecimentos alimentares não conformes com a infra-estrutura, manuseio higiênico sanitária e biossegurança. Conclusão: comportamentos negativos são vistos em auto-cuidado da saúde sexual e da saúde reprodutiva, a má gestão com a amamentação e alimentação complementar, cuidar de animais de estimação e pobres práticas de higiene saneamento nos estabelecimentos alimentares, que deve ser reconsiderada para melhorar estilos estilos de vida saudáveis.

PALAVRAS-CHAVE: autocuidado, assunção de riscos, estilo de vida. 


\section{INTRODUCCIÓN}

Ene - Jun 2016

Cúcuta, Colombia as características sociopolíticas del entorno y condiciones de vida de la población o las circunstancias en que les corresponde vivir desde que se nace, crece, vive, trabaja y envejece, junto con las particularidades individuales, van determinando el modo de vida de un colectivo o grupo social (1).

El estilo de vida es la conducta individual de la manera de ser y de comportarse, mediada por la personalidad, que se comparte dentro de una sociedad que se parece entre sí por sus características sociodemográficas, psicológicas, de comportamiento, de equipamiento e infraestructura, entre otras (2), dando uso a los diversos medios que su entorno y la sociedad a la que pertenece le ofrece para satisfacer sus necesidades básicas (3); por su parte, el modo de vida lo constituyen las diversas maneras de adaptación de los colectivos para habitar el entorno (4). Los estilos y modos de vida, a su vez, influyen en las expresiones de salud y de enfermedad en las personas

Desde las experiencias de los estilos y modos de vida, el sujeto percibe la calidad de vida y los factores de riesgo dados desde las características sociodemográficas y del entorno social (5) para determinar las características de su cuidado (6), adaptándolos o no a las condiciones de vida, de trabajo, del nivel de ingresos y del nivel educativo, entre otros.

Las tasas de mortalidad y natalidad en el año 2012, en Valledupar, disminuyeron debido a la desaceleración del crecimiento poblacional de niños y jóvenes menores de 20 años y al aumento de la población mayor de 30 años. Este indicador sociodemográfico es una ventaja potencial por la menor proporción de población que requiere inversiones en educación y salud, posibilitando un mayor crecimiento económico, al mismo tiempo que aumenta en 2.4 $\%$ la población económicamente activa (PET) y la tasa de desocupación disminuye de $19.7 \%$ a 10.1 $\%$, siendo una de las más bajas de la región (7). Esta situación hace necesario indagar si las condiciones en el mercado de trabajo son las adecuadas para mejorar los ingresos de los hogares $\mathrm{y}$, en consecuencia, mejorar también su calidad de vida e impactar en los niveles de pobreza del municipio.
En Valledupar, en el 2014, aún no se cumple con los Objetivos del Milenio: en cuanto al nivel de educación básica primaria sólo se alcanzó el 81 $\%$, en secundaria se llegó al $70 \%$ y en educación media al $39 \%$, indicadores desalentadores que están relacionados con las condiciones de infraestructura, la baja calidad de las redes eléctricas, la seguridad y el aumento de la drogadicción (8), aspectos que ya habían sido vislumbrados por la Organización de las Naciones Unidas, entidad que advirtió sobre la necesidad de desarrollar estrategias de intervención colectiva e individual, involucrando tanto al sector salud como a otros sectores (7), para hacer más eficaz y eficiente el esfuerzo interinstitucional con su respectiva responsabilidad social (9).

La unión de las personas, las instituciones, los grupos sociales y las familias de la comunidad facilita la intervención colectiva en consenso y fomenta la cultura ciudadana. Debido a que Valledupar es una ciudad intermedia con crecimiento urbanístico y marcados procesos de aculturación influenciados por la migración de diversos grupos sociales y educativos, con modos de vida y formas de autocuidado, estos factores van caracterizando estilos de vida deficientes relacionados con el cuidado de la vida y la salud y repercuten en la forma de organizarse productivamente en una economía de sobrevivencia (10).

El anterior contexto influye en la constitución de la familia, la cual se fortalece mediante relaciones de solidaridad entre miembros que comparten algún vínculo de identidad, tales como los sentimientos de convergencia y afecto, creando una dinámica grupal que va más allá de una relación basada en la consanguinidad, aunque en su concepto está tradicionalmente constituida por el grupo de personas que proceden de los progenitores (sentido amplio) en donde las relaciones jurídicas que existen entre sus miembros tienen como fuente el matrimonio y la filiación matrimonial o extramatrimonial (11). En este sentido, el estudio asume como integrante de la familia a toda persona que se integra, ya sea por consanguinidad o no, y que por lazos de solidaridad pertenece y es reconocido como tal.

Por esta razón surge el interés de desarrollar la investigación que sustenta este artículo, con el propósito de determinar los factores de riesgo que afectan la calidad de vida y comportamiento de riesgo más prevalente en sus estilos de vida, por 
estrato socioeconómico, como aporte significativo al conocimiento sobre la problemática social, como herramienta pedagógica para el desarrollo del pensamiento crítico y creativo de los estudiantes y como espacio de motivación y orientación para la realización de proyectos de desarrollo comunitario encaminados a favorecer la adopción de prácticas y hábitos saludables.

\section{MATERIALES Y MÉTODOS}

Se realizó un estudio con enfoque cuantitativo que permitió el análisis de una realidad observable y medible. El método utilizado fue descriptivo, de corte transversal (12) puesto que su diseño fue observacional, individual y de corte o momento determinado de tiempo en el diario vivir de los informantes, identificando o describiendo de manera predominante las condiciones, el lugar o factores de riesgo, cuya finalidad es el estudio de la frecuencia y distribución de eventos de salud y enfermedad.

Para la selección de las familias se aplicó el muestreo estratificado, sistemático y aleatorio simple, siempre que reuniera los criterios de selección: que el informante habitara la vivienda y fuese integrante de la familia a la que representaría, mayor de 18 años, disposición y responsabilidad para aportar datos, previa orientación del valor del estudio.

El método estratificado permitió visibilizar cómo se comporta una característica o variable por estrato, dado por servicios públicos de la ciudad, como mejor vía a seguir para el análisis de datos derivados de un muestreo probabilístico; también para visibilizar cómo se comporta una característica o variable en una población, haciendo evidente el cambio de dicha variable en los diferentes estratos socioeconómico, igualmente como mejor opción para el análisis de datos derivados de un muestreo probabilístico. Los datos fueron suministrados por el Departamento Administrativo Nacional de Estadística (DANE).

Para la selección de la muestra (familia por vivienda) se consideró la identificación de todos los barrios por estrato socioeconómico, información suministrada por el Instituto Geográfico Agustín Codazzi y la Oficina de Planeación Municipal. Este proceso permitió identificar dicha muestra a partir de la estratificación, de acuerdo con los servicios públicos del municipio, asumiendo que una familia está compuesta, en promedio, por 4.5 personas, con el criterio de seleccionar a una familia por vivienda y dos por barrio y estrato del total de viviendas. Según datos del Acueducto de Valledupar, se registran 20.646 familias de todos los estratos socioeconómicos en la comuna tres, ubicados en los 10, 13 y 8 barrios para estrato 1, 2 y 3 respectivamente, con una población correspondiente a $3.923,11.149$ y 5.575 personas, obteniendo una muestra representativa y seleccionada con método aleatorio simple de 68 familias.

La proporción de unidades en cada uno de los estratos poblacionales fue:

$$
\begin{aligned}
& \mathrm{W}_{1}=\mathrm{N}_{1} / \mathrm{N}=3923 / 20647=19 \% \\
& \mathrm{~W}_{2}=\mathrm{N}_{2} / \mathrm{N}=11149 / 20647=54 \% \\
& \mathrm{~W}_{3}=\mathrm{N}_{3} / \mathrm{N}=5575 / 20647=27 \%
\end{aligned}
$$

N1 $=3.923$ Personas, N2=11.149 Persona, N3 $=5.575$ Personas para un $\mathrm{N}=20.647$ de personas en total en que, según DANE 2005, el promedio de personas por familia es 4.5 , representaría a 4.588 familias en los tres estratos;

$$
\mathrm{n}=\quad \begin{aligned}
& \mathrm{N} * \mathrm{Z}^{2} * \sum \mathrm{w}_{\mathrm{h}} \mathrm{S}_{\mathrm{h}}{ }^{2} \\
& \mathrm{~N} *-------------------- \\
& \mathrm{N} * \mathrm{Z}^{2}+\mathrm{Z}^{2} \sum \mathrm{w}_{\mathrm{h}} \mathrm{S}_{\mathrm{h}}{ }^{2}
\end{aligned}
$$

Donde:

$\mathrm{n}$ : Es la muestra por personas a encuestar, $\mathrm{N}$ : Es el total de la población, $\mathrm{S}_{\mathrm{h}}{ }^{2}$ : Varianza de cada estrato, $\sum \mathrm{w}_{\mathrm{h}}$ : Proporciones de unidades en cada uno de los estratos poblacionales y z : es el intervalo de confianza en donde caen las unidades de estudio. A los resultados de tablas dadas en frecuencias se les aplicó la medida de tendencia central: media. El tamaño de la muestra fue $n \approx 68$ familias, $y$ con repartición proporcional para cada estrato se tuvo la siguiente fórmula proporcional:

$\mathrm{n}_{\mathrm{h}}=\mathrm{nX} \mathrm{W}_{\mathrm{h}}$

donde

$\mathrm{n}_{1}=20$ Famílias,

$\mathrm{n}_{2}=37$ Famílias $\mathrm{y}$

$\mathrm{n}_{3}=11$ Famílias

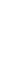


E-ISSN 2322-7028

Vol. 13 No. 1

Ene - Jun 2016

Cúcuta, Colombia
Para la valoración higiénico sanitaria de expendios de alimentos se tuvo en cuenta la percepción de los líderes comunitarios y la valoración por expertos, obteniendo como muestra a 31 presidentes de juntas de acción comunal de los estratos en mención y al líder de la Junta Administradora Local, representante de la comuna, como parte de la población de referencia para suministrar información requerida en los barrios y estrato socioeconómico correspondientes.

Los líderes seleccionados fueron tres por comuna, escogidos por conveniencia, previa ilustración del consentimiento informado y libre participación en el estudio, para integrar a la muestra a 18 presidentes de juntas de acción comunal en las 6 comunas, distribuyéndose 6 para cada estrato, es decir, un líder de cada comuna valoraba a cada tipo de expendio (tienda, restaurante de cárnicos o lácteos) $\mathrm{y}$, posteriormente, se corroboraba con expertos del programa de microbiología de la universidad a 18 expendios de cada tipo, correspondiendo, por estrato y por comuna, valorar una tienda, un restaurante y un expendio de cárnicos o lácteos, para un total de 54 expendios

Las distribuciones muestrales permitieron analizar las diferencias comportamentales de cada variable en cada comuna, siendo vitales para comprender la inferencia estadística y para extrapolarlos a toda la población. En el estudio se utilizó el método sistemático para organizar la ubicación de la fuente primaria, asignando una rotulación en el mismo sentido en todas las distribuciones muestrales, iniciando la primera al azar.

La aplicación del método aleatorio simple consistió en la selección de $\mathrm{n}$ unidades sacadas de $\mathrm{N}$, de tal manera que cada una de las muestras tuviese la misma probabilidad de ser elegida. En la práctica, una muestra aleatoria simple es extraída de la siguiente forma: se enumeran las viviendas, en este caso del 1 al $\mathrm{N}$ y, por medio de una tabla de números aleatorios o colocando los números 1 a $\mathrm{N}$ en una urna, se extraen sucesivamente $\mathrm{n}$ números; las unidades que llevaban estos números constituyeron la muestra, representada en una familia por vivienda.

Este método permitió verificar que, en cualquier fase de la obtención de la muestra, cada vivienda no fuera eliminada previamente y tuviese la misma probabilidad de ser elegida. Se tuvo en cuenta que cuando un número hubiese sido sacado de la urna no fuera reemplazado, evitando que la misma unidad entrara en la muestra más de una vez; por esta razón, el muestreo fue descrito como sin reemplazo.

La ubicación de los barrios por estrato socioeconómico se obtuvo a partir de la información suministrada por el Instituto Geográfico Agustín Codazzi y la Oficina de Planeación Municipal, siendo necesario localizar en un mapa (13) los barrios correspondientes a la Comuna Tres objeto de este estudio, en aras de garantizar la objetividad y precisión del trabajo de campo por parte de los estudiantes y docentes asignados para dicha labor. Posteriormente se aplicaron los instrumentos respectivos, teniendo en cuenta el método sistemático y aleatorio simple.

Los criterios de inclusión para la información de la encuesta Alfabeta fueron: mayor de 18 años, representantes por barrio y de la comuna 3 , indistinto su sexo, libre participación, más de un año como residente, una persona informante por vivienda. Para la valoración higiénico sanitaria de expendios de alimentos: dos expendios por cada tipo y estrato socioeconómico y consentimiento informado por parte de su propietario. El estudio contempló como familia a miembros que suelen compartir la misma residencia y giran en torno a patrones de cuidado y valores de crianza compartidos, ingresos para manutención sin necesidad de lazos consanguíneos.

Los instrumentos utilizados en el estudio fueron elaborados desde la experticia de cada disciplina: ingeniería ambiental, ingeniería agroindustrial, microbiología, enfermería e instrumentación quirúrgica para determinar la validez de contenido, teniendo en cuenta el juicio y aportes de dichos expertos en el tema, quienes valoraron la matriz de consistencia a partir del problema, objetivos y variables, además de determinar la coherencia entre ellos. Sus variables fueron tanto cualitativas nominales, dicotómicas y politómicas como cuantitativa discretas, haciendo la respectiva prueba piloto. La codificación de estas variables se hizo con el programa Excell 2013 y el programa estadístico SPSS versión 12 .

Dentro de los instrumentos utilizados en el estudio se encuentra la encuesta estructurada denominada Riesgos en la vida cotidiana de los habitantes del área urbana de la Comuna Tres de Valledupar según 
estrato socioeconómico 2013, que, tras la aplicación de la prueba piloto, aseguró la confiabilidad y validez del estudio. En ella se analizaron las siguientes variables: caracterización sociodemográfica de la población, condiciones de vida y cuidado de la salud.

Para la valoración por parte de expertos de las condiciones higiénico sanitarias de los expendios de alimentos se elaboró una lista de chequeo denominada Condiciones Higiénico Sanitarias de los Centros de Servicio y Expendios del Área Urbana de Valledupar 2013, que contempló subvariables relacionadas con las condiciones básicas sanitarias locativa y de higiene en el manejo y preparación de alimentos en los diferentes expendios -tiendas, restaurantes y ventas de lácteos y productos cárnicosexistentes en los barrios y estratos socioeconómicos I, II y III, valorados por estudiantes y docentes del programa de microbiología, con su respectiva prueba piloto, acogiendo la normativa sobre prácticas de manufactura del Decreto 3075 de 1997 (14).

En el proceso de interpretación y análisis se tuvo en cuenta el análisis univariado y bivariado desde la mirada holística (15) que asegurara recomendaciones integrales. Para facilitar el análisis, consolidación y procesamiento de la información recolectada en los instrumentos fue necesario agotar una serie de pasos que permitieron encontrar patrones de coincidencia entre unidades poblaciones de los tres estratos socioeconómicos establecidos con base en los valores de los distintos temas de análisis (16).

Esta formulación permitió generar escenarios homogéneos a los cuales se pudo atribuir la manifestación de problemas de salud similares y también sus factores de riesgo comunes y atribuibles, teniendo en cuenta la no homogenización de la multicausalidad, tolerando algunos grados de disentimiento del patrón principal de riesgos para formular propuestas explicativas e hipótesis de riesgos con la opinión de expertos, con los hechos comprobables en otras realidades en el país y con lo reportado en la bibliografía mundial, ajustando esquemas e hipótesis en función a estas nuevas fuentes de información que permitirán, en estudios siguientes, abordar la problemática social desde la comprensión de los fenómenos (17), con el fin de ser mayormente asertivos en contenidos educativos diferenciados en un futuro inmediato.
El Comité de Investigación de la Facultad Ciencias de la Salud aprobó el uso de los instrumentos con el rigor ético debido en el modo de aplicarlos, guardando la privacidad de la identificación de los informantes y nombre de expendios, además del consentimiento informado de los informantes obtenido al momento del trabajo de campo realizado por los estudiantes investigadores. No se necesitó permiso institucional, por cuanto la información fue tomada directamente de los habitantes y de los manipuladores de alimentos, quienes son los dueños de los mismos expendios. Igualmente, se tuvo en cuenta lo establecido en la Resolución No. 008430 de 1993 (18) en la cual se establecen las normas científicas, técnicas y administrativas para la investigación en salud.

\section{OBJETIVOS}

\section{Objetivo general}

Determinar los principales factores de riesgo que afectan la calidad de vida que asumen en el cuidado de la salud los habitantes del área urbana de Valledupar, para los estratos socioeconómicos 1, 2 y 3 de la Comuna Tres.

\section{Objetivos específicos}

- Caracterizar los factores de riesgo en la vida cotidiana de cada familia, relacionados con su situación sociodemográfica.

- Caracterizar los factores de riesgo en la vida cotidiana de cada familia, relacionados con sus condiciones de vida.

- Caracterizar los factores de riesgo en la vida cotidiana de cada familia, relacionados con el cuidado de la vida y la salud.

- Identificar los factores de riesgo relacionados con las condiciones higiénico-sanitarias de los diferentes expendios de alimentos reconocidos por las familias, líderes y expertos en el tema.

\section{RESULTADOS}

Se presentaron dificultades por parte de los coordinadores de cada barrio, durante la fase de aplicación de los instrumentos para la selección inicial de la familia por vivienda, las cuales se

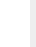


subsanaron con la entrega del mapa por comuna y número de viviendas por barrio que incluyera a la persona que reuniera los criterios de selección. Para garantizar la veracidad de la información, el equipo investigador rastreó encuesta por encuesta valorando coherencia de los datos y, al encontrar inconsistencias, se tomaban nuevamente los datos del mismo estrato socioeconómico -y a la misma familia, en lo posibleregistrando la dirección de la fuente. Esta información se recolectó durante el segundo semestre de 2014, con la participación de estudiantes y docentes de la Facultad de Ciencias de la Salud.
A continuación se esbozan los riesgos que asumen las personas dentro de las familias, en el cuidado de la salud con mayor valoración respectiva:

\section{Características sociodemográficas}

El género femenino es mayoritario, equivalente a un $53.4 \%$. Se estudiaron 28 categorías de las cuales 10 de ellas son las más prevalentes:

Tabla 1. Principales factores de Riesgo de acuerdo a las características sociodemográficas.

\begin{tabular}{|c|c|c|c|c|}
\hline \multirow[t]{2}{*}{$\begin{array}{l}\text { Factores de riesgo según categorías de } \\
\text { la variable sociodemográfica }\end{array}$} & \multirow[t]{2}{*}{ Comuna } & \multicolumn{3}{|c|}{$\begin{array}{l}\text { Estrato mayor- } \\
\text { mente afectado }\end{array}$} \\
\hline & & 1 & 2 & 3 \\
\hline $\begin{array}{l}\text { Máximo nivel de formación alcanzado a } \\
\text { la fecha del estudio }\end{array}$ & $\begin{array}{l}\text { la mayor formación académica partiendo de los } 16 \text { años en adelante es el } \\
\text { nivel técnico en un } 41 \% \text { y de profesionales en un } 16 \%\end{array}$ & & $\mathrm{X}$ & \\
\hline $\begin{array}{l}\text { Mayor ocupación según género y perso- } \\
\text { nas por familia que generan ingresos }\end{array}$ & $\begin{array}{l}59 \% \text { de las familias tienen como mínimo a dos de sus integrantes gene- } \\
\text { rando ingresos con trabajo de mano de obra no calificada. } \\
\text { Mujeres trabajan en oficios doméstico o son amas de casa en un } 24 \% \text { y } \\
\text { los hombres en un } 31.6 \% \text { en oficios varios del total de las ocupaciones } \\
\text { de estas familias }\end{array}$ & & $\mathrm{X}$ & $\mathrm{X}$ \\
\hline $\begin{array}{l}\text { Género por jefatura en el hogar y estado } \\
\text { civil }\end{array}$ & $\begin{array}{l}25 \% \text { de las familias la jefatura del hogar es una mujer, de los cuales el } \\
53 \% \text { son por separación y un } 17 \% \text { por viudez. }\end{array}$ & & $\mathrm{X}$ & \\
\hline $\begin{array}{l}\text { Insatisfacción según promedio de in- } \\
\text { gresos }\end{array}$ & $\begin{array}{l}61 \% \text { de las familias reciben ingresos entre } \$ 500.000 \text { a } \$ 900.000 \text { y consi- } \\
\text { deran no ser suficiente }\end{array}$ & & $\mathrm{X}$ & $\mathrm{X}$ \\
\hline Medio de transporte más utilizado & $100 \%$ prefieren la moto y el taxi colectivo & & $X$ & \\
\hline Presencia menor trabajador & $5 \%$ de las familias del estrato uno y $1.5 \%$ del total de la comuna. & $\mathrm{X}$ & & \\
\hline Seguridad ciudadana & $\begin{array}{l}53 \% \text { y } 22 \% \text { de los encuestados afirman que la inseguridad es más dada } \\
\text { por vandalismo y muertes violentas, respectivamente. }\end{array}$ & & & \\
\hline $\begin{array}{l}\text { Problemas sociales reconocidos del } \\
\text { barrio }\end{array}$ & $\begin{array}{l}74 \% \text { el consumo y venta de alucinógeno, } 72 \% \text { dice que la prostitución } \\
\text { y el } 56 \% \text { pandillas como mayor problema social }\end{array}$ & & $\mathrm{X}$ & \\
\hline $\begin{array}{l}\text { Estado y uso de los parques o zonas de } \\
\text { recreación }\end{array}$ & $\begin{array}{l}95 \% \text { de las familias expresó que los espacios públicos como los par- } \\
\text { ques, en su mayoría, no son utilizados debido a las condiciones de } \\
\text { deterioro e inseguridad en que se encuentran, que no se garantiza el } \\
\text { acceso a ellos de manera segura, adecuada y sostenible como escenarios } \\
\text { recreativos públicos }\end{array}$ & & $\mathrm{X}$ & $\mathrm{X}$ \\
\hline Cultura ciudadana & $\begin{array}{l}68 \% \text { de los encuestados reconoce las organizaciones comunitarias y, de } \\
\text { ellos, el } 82 \% \text { no participa en sus reuniones }\end{array}$ & & $\mathrm{X}$ & \\
\hline
\end{tabular}

Fuente: Instrumento Riesgos en la vida cotidiana de los habitantes del área urbana de la Comuna Tres de Valledupar según estrato socioeconómico, 2013.

El mayor nivel educativo que ha alcanzado la población estudiada es la formación técnica en un $41 \%$ (ver tabla 1), la ocupación que desarrollan estas familias tiene género, es decir, las mujeres que trabajan lo hacen en el servicio doméstico o como amas de casa, mientras que los hombres se ocupan en oficios varios siendo el de mayor aporte, en los informantes con edades entre 26 y 35 años de edad, la presencia de un menor trabajador desempeñándose en oficios varios, perteneciente al estrato dos.

El tipo de transporte más utilizado es el taxi colectivo o moto taxi, puesto que el transporte público es deficiente. La seguridad ciudadana se ve afectada por la venta de alucinógenos, la prostitución y el vandalismo. El pandillismo es el mayor problema 
social reconocido en el estrato dos. El estado y uso de los parques o zonas paisajísticas es precario, con escaso mantenimiento, lo cual hace que estos lugares sean propicios para actos de violencia. La participación en la toma de decisiones respecto a los intereses comunitarios forma parte de la órbita de la cultura ciudadana que se caracteriza por reconocer la misión de sus organizaciones comunitarias y de participar en ellas. Sin embargo, el $82 \%$ de los informantes no participa y se justifica en la falta de tiempo $(50 \%)$ o porque no le gusta $(23.5 \%)$.

\section{Condición de vida}

Se consideraron 48 categorías, de las cuales 20 fueron mayormente reconocidas como riesgo. El 50 $\%$ de los encuestados reconoce que la educación es ofrecida por el estado y, en segundo lugar, por grupos religiosos con mayor aporte a la formación preescolar, educación básica primaria y secundaria. Entre el $75 \%$ y el $100 \%$ de los líderes afirma que ninguna institución del Estado lidera actividades productivas para el tiempo de ocio de jóvenes y adultos mayores; sin embargo, todos coinciden en que la religión, como institución, es la que está presente con actividades netamente religiosas.

El $95 \%$ de las familias expresó que espacios públicos como parques o zonas paisajísticas, en su mayoría, no son utilizados debido a las condiciones de deterioro e inseguridad en que se encuentran, hecho que no los garantiza de manera segura, adecuada y sostenible como escenarios recreativos públicos, en virtud de su deficiente infraestructura, amueblamiento y mantenimiento precario que afectan la integración, especialmente, entre el estrato 1 y 2.

El $100 \%$ de los líderes reconoce que la causa de la contaminación del aire son los gases vehiculares, seguida por la quema de basuras y la presencia de animales muertos a campo abierto (75\%) y la descomposición de residuos orgánicos ocasionado por la actividad humana (50\%).

El $50 \%$ de los líderes respondió que la contaminación de suelos se presenta por sobrepastoreo, excretas y presencia de aguas residuales a campo abierto, un $25 \%$ afirma que es por lixiviados en cuerpos de agua superficiales, en aguas subterráneas y por uso de plaguicidas e insecticidas, contaminación que afecta tanto al hombre como a la flora y la fauna, disminuyendo la variedad de especies que empiezan a tener dificultades en su proceso natural. Acerca de los servicios públicos, se encontró que un $3 \%$ de las familias por vivienda no tiene acceso al servicio de recolección de basuras.

E1 $50 \%$ de las familias posee vivienda propia, el 72.1 $\%$ no tiene internet en su casa y el $29 \%$ tiene techos de zinc en sus hogares -esto último factor de riesgo para la salud en virtud de los cambios homeostáticos que, de acuerdo con las formas de pérdida de calor, puede alterar los mecanismos fisiológicos y causar inestabilidad de las condiciones metabólicas, neurológicas y cardiovasculares, debido la baja capacidad que tiene al calentarse por encima de la temperatura ambiental durante el día y enfriarse en la noche, de tal manera que no aísla del calor ni del frío, se oxida fácilmente en zonas húmedas o épocas de alta lluviosidad y se deteriora por la misma cantidad de minerales presentes en el ambiente (19).

El $79 \%$ de los informantes de las familias reconoce que recibe subsidio en servicios de salud o familias en acción. El problema de los asentamientos encontrados en los estratos 1 y 2 se presenta en un $13 \%$ por desplazamiento y en un $15 \%$ por hacinamiento, con consecuencias para la salud familiar y pública, consideradas dentro de los determinantes sociales (20).

El $50 \%$ de las familias que tiene de 1 a 4 integrantes es el grupo con mayor número de afiliaciones al sistema de salud, con mayor presencia en el estrato dos, porque es allí donde se presentan mayores niveles de empleo. Lo contrario ocurre en aquellas familias compuestas por 5 a 8 integrantes, que no están cubiertas por el sistema general de seguridad social en salud y atribuyen esa situación a la inoperancia de sus funcionarios, problemas de accesibilidad, falta de oportunidad de la atención, baja información u orientación o por la calidad humana.

El $79 \%$ de la población está afiliada al Sistema de Potenciales Beneficiarios para Programas Sociales (SISBEN) y un $16 \%$ al régimen contributivo por trabajo independiente. La comunidad espera que el Estado le proporcione los servicios de salud a través de sus líderes políticos de turno por medio del empleo, fenómeno que se observa preponderantemente en el estrato 2 .

(1)


El $75 \%$ de las familias afirma que son los mismos moradores quienes están produciendo más daño ecológico. La contaminación del agua se origina por fuentes físicas, químicas y biológicas. Además, esas familias no hacen mantenimiento a las zonas verdes de su propiedad, favoreciendo los actos vandálicos y la violencia sexual. El $75 \%$ de los informantes afirma que la contaminación del aire es ocasionada por los gases de vehículos de personas ajenas a su comunidad.

El $50 \%$ de los líderes comunitarios manifiesta que para almacenar el agua utiliza albercas y utensilios de cocina en condiciones sanitarias deficientes. Estas prácticas están relacionadas con las costumbres de una comunidad que no es consciente de mantener buenos hábitos sanitarios para el bien común, lo cual genera un impacto negativo en la salud pública (21).

\section{Prácticas de cuidado}

Se contempló desde la mirada ontológica del cuidado de la vida, teniendo como subvariables: el autocuidado, el cuidado primario, el cuidado doméstico y el cuidado con su entorno natural. El autocuidado se refiere a las actividades que realizan para el cuidado de sí mismos; el cuidado primario es el cuidado proporcionado a los niños, adultos mayores y a los discapacitados, es decir, la atención que se ofrece a integrantes que por sus condiciones físicas, ciclo vital o fisiológicas poseen alguna dependencia; el cuidado doméstico está relacionado con las medidas de aseo y control sanitario de la vivienda, entorno natural y de los animales domésticos; y, por último, el ejercicio de ciudadanía traducido en el aporte a la cultura ciudadana como expresión de comportamientos para la convivencia pacífica en respuesta del valor por el otro, reflejado en su integración a los procesos de participación comunitaria e integración al cuidado, en casos de desastres naturales o emergencias, de los procesos de ciudadanía y preparación para ser asumidos con responsabilidad.

Esta variable de cuidado, vista desde lo integral, contempló un total de 58 subvariables, distribuidas respectivamente en $25,19,9$ y 5 , de las cuales presentaron como factores de riesgo 16 en autocuidado, 8 en cuidado primario, 4 en cuidado doméstico y 2 en cultura ciudadana (Ver Tabla 2).

Con relación al autocuidado, en las familias se obser- va que el $8.8 \%$ de las mujeres se encuentra es estado de embarazo, el $24.1 \%$ es adolescente y el $44 \%$ del total de embarazadas no asiste al programa de control prenatal, sobre todo quienes viven en el estrato dos. De las mujeres inscritas en el programa de planificación familiar, el $60.3 \%$ usa el método hormonal, especialmente en el estrato dos.

El $63 \%$ de las familias que reconoció la práctica de automedicación realiza la compra en una droguería, con mayor frecuencia en los habitantes del estrato uno y dos. El 80.9 \% de los informantes manifestó que sus familias no realizan actividades productivas en el tiempo libre.

\section{Cuidado primario}

E1 $26.5 \%$ de los encuestados manifiesta que tiene bajo su cuidado a adultos mayores: por cada 4 viviendas, un adulto mayor como mínimo. De ellos, sólo el $24 \%$ se practicó examen de próstata y el $63.1 \%$, perteneciente al estrato dos, presentó enfermedades del sistema cardiovascular, mientras que un $21 \%$ evidenció enfermedades gastrointestinales, factor predominante en el estrato tres. 
Tabla 2. Principales factores de riesgo en el cuidado de la salud.

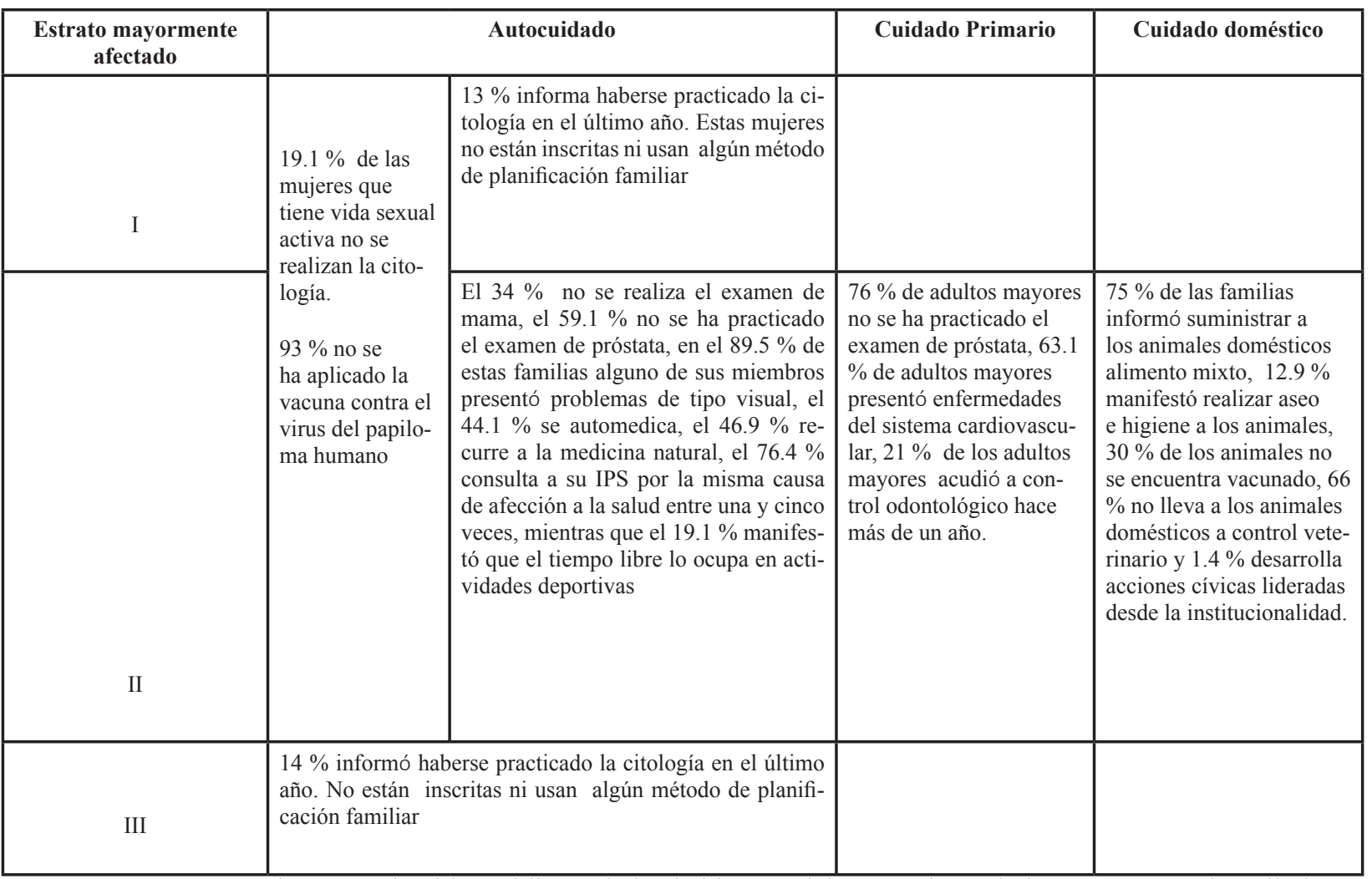

Fuente: Instrumento Riesgos en la vida cotidiana de los habitantes del área urbana de la comuna tres de Valledupar según estrato socioeconómico, 2013.

El $53.1 \%$ de las familias no usa la medicina natural, especialmente los del estratos dos, y un $56.5 \%$ de la población afirma realizar combinaciones entre la medicina natural y la terapia farmacológica, con un mayor predominio en el estrato dos.

El $51.5 \%$ usa los servicios de consulta general antes de que se generen secuelas o complicaciones. El 29.4 $\%$ de las familias provenientes del estrato dos, que tiene hijos, consulta con más frecuencia a las instituciones prestadora de servicios de salud (IPS).

El $70 \%$ de familias estudiadas brindó lactancia materna en el rango de edad de 3-6 meses de edad de sus hijos, con predominio en el estrato dos; el restante $30 \%$ de la población sigue brindando lactancia materna exclusiva hasta el año, siendo prejudicial para el crecimiento y desarrollo al no recibir una adecuada y completa alimentación. En el 1.6 \% de las familias hay niños con problemas de lenguaje, pertenecientes al estrato dos, al igual que con dificultades en su desarrollo motor, cuyas edades oscilan entre 1 a 4 años.

\section{Cuidado doméstico}

En esta subvariable los comportamientos de riesgo más destacados se presentan en torno al cuidado que se les brinda a los animales domésticos: el tipo de alimento más ofrecido es el mixto (76\%) con predominio en el estrato dos, el $66 \%$ informa que no los lleva a control veterinario, el $76 \%$ deja a los animales realizar sus necesidades a campo abierto, especialmente los habitantes de los estratos uno y dos, mientras que el $79 \%$ no practica normas de convivencia y adiestramiento, sobre todo en el estrato uno.

El $25 \%$ de las familias, de todos los estratos socioeconómicos, informó que en el barrio existen diferentes factores de riesgo tales como deslizamiento, atentados, incendios y atracos.

Ninguno reconoce su compromiso frente al cuidado doméstico relacionado con los animales, con el control de basuras o con los procesos de participación comunitaria para abordar los problemas que les afecta 
desde lo colectivo y la importancia del mismo dentro de la comunidad, lo cual podría aseverar su apatía o enajenación. No se percibe interés por adquirir responsabilidad para colaborar como voluntario en la atención frente a desastres naturales que podrían presentarse en la comunidad y que podrían afectar a sus familias.

La distancia aceptable entre equipos eléctricos es de un metro como mínimo dentro de una vivienda: el $40 \%$ de las familias los mantiene a menos de un metro, constituyéndose en un factor de riesgo para la accidentalidad de tipo doméstico. El 55.4. \% de las familias los tiene ubicados dentro de los parámetros establecidos como ideal para la prevención de riesgos.

\section{Prácticas higiénicas sanitarias en expendio de ali-} mentos

La valoración de las condiciones básicas sanitarias y de higiene de los diferentes expendios de alimentos, realizada por expertos en la materia, permitió deducir que no se están aplicando las normas y reglamentos en materia de higiene de alimentos, desde la producción primaria hasta el consumidor final, destacando los controles básicos de higiene que se efectúan en cada etapa.

Para la salud pública es importante focalizar epidemiológicamente los diversos riesgos presentes debido a las condiciones sanitarias deficitarias e implicaciones y consecuencias en la salud humana y ambiental, así:

- Estructura locativa y su condición sanitaria: el $53.7 \%$ de los expendios valorados reconoce que no cumple con las normas higiénico sanitarias, sobre todo los expendios ubicados en los estratos 1 y 2 .

- Condición sanitaria del acceso y ambiente locativo: se encontró que el $68.5 \%$ de los expendios valorados no cumple ni aplica manejo sanitario adecuado, sobre todo aquellos ubicados en el estrato 3, a pesar de que esta población es considerada como de mejor nivel educativo, mayores ingresos y mejor ubicación.

- Medidas de protección o bioseguridad que adoptan los trabajadores en los diferentes expendios de alimentos, al realizar sus labores: en el $53.7 \%$ de los expendios sus trabajadores cumplen con la adopción de medidas de bioseguridad, en especial aquellos ubicados en el estrato tres.

- De las condiciones de infraestructura de los diversos tipos de expendios de alimentos (tiendas, restaurantes, expendios de cárnicos o lácteos), el $75.9 \%$ no cumple con estos aspectos, especialmente los que están ubicados en los estratos 1 y 3 .

\section{DISCUSIÓN}

\section{Características sociodemográficas}

En los estratos que componen la sociedad, los individuos se diferencian por la forma de comprender el mundo y su actuar, lo que determina la forma en la que ellos organizan su cultura; en este sentido, el tiempo de ocio también debe ser productivo para el crecimiento personal, de manera creativa, desarrollando capacidades, favoreciendo el equilibrio personal y enriqueciendo su experiencia de vivir.

La ausencia institucional para hacer productivo el tiempo de ocio de los habitantes y la baja capacidad de oferta y diversidad de programas académicos en la región genera una población vulnerable en el presente, evidente en el aumento de consumo de licor, inversión de tiempo de ocio en juegos de azar, baja capacidad de ingresos -en un $51.9 \%$ inferior a $\$ 300.000$ para su sustento- que el $48.1 \%$ invierte prioritariamente en salud, probablemente por las condiciones de vida.

En este sentido, el Estado debe reivindicar en la ciudadanía el valor del uso del tiempo de ocio. Desde la perspectiva comunitaria, el empoderamiento se utiliza para estudiar procesos de trabajo con grupos minoritarios, no empoderados (mujeres, grupos de bajos ingresos económicos, etc.), considerando el empoderamiento como el desarrollo de estrategias dadas desde agencias multilaterales de desarrollo, como un componente fundamental en las estrategias de erradicación de la pobreza (22).

El bajo nivel educativo y la debilidad estatal para ofrecer educación para el trabajo, además de la presencia de habitantes con mano de obra no calificada para atender la demanda local en la 
explotación minera y agrícola, entre otras razones, afecta el desarrollo que, junto con el desempleo y aumento de inmigrantes con mano de obra calificada, produce efecto un negativo sobre la calidad de vida de los nativos, por cuanto ellos no tendrán mejores condiciones de vida.

Al respecto, el Ministerio de Educación Nacional (23) argumenta que la educación media en el país (grados $10^{\circ}$ y $11^{\circ}$ ) alcanza apenas una cobertura del $41 \%$. El retiro de los jóvenes de las aulas de clase se da en este nivel -considerado como una etapa clave para el fortalecimiento de las competencias cognitivas y socioemocionales, fundamentales para el desarrollo de posteriores competencias laborales-, fenómeno que plantea la necesidad de cerrar diferencias entre la educación media que se ofrece y se recibe en las áreas rurales y aquella que se ofrece en el área urbana, en diferentes estratos socioeconómicos, con el propósito de generar igualdad de oportunidades a todos los jóvenes del país .

Por otro lado, las mujeres cabeza de hogar que están en edades entre los 45 y los 60 años carecen de la experiencia laboral necesaria para insertarse en el mercado de trabajo y nunca se incorporaran a la población económicamente activa debido a que, además, no poseen formación académica que permita mejorar sus condiciones de vida, siendo un factor de riesgo al tornarse económicamente dependientes de los hijos cuando hay desempleo, son mano de obra no calificada y sus ingresos no alcanzan a cubrir gastos mínimos de sostenimiento. El acceso a un empleo decente se hace especialmente difícil para las mujeres, por lo cual su instalación como visión estratégica demanda también una perspectiva de género que debe ser incluida en las políticas públicas, como lo reconoce la Organización de las Naciones Unidas (24).

La encuesta realizada por Demografía y Salud en Colombia, en el año 2010 (25), afirma que las mujeres del país han sufrido transformaciones sociales y culturales sobre los roles que ejercen en la sociedad; esto se evidencia, entre otras cosas, en el crecimiento (en un $5 \%$ ) del fenómeno de jefatura femenina en los hogares durante el periodo intercensal 1993-2005. En este fenómeno creciente, no sólo en Colombia sino también en toda Latinoamérica, el $33 \%$ de las mujeres colombianas prefiere mantenerse con sus parejas en unión libre a estar casadas y el $74 \%$ de ellas está divorciada o separada, evidenciándose una transformación en las estructuras de género, y en la familia en general, como lo afirma Velásquez (26). que el crecimiento del $5 \%$ del fenómeno de jefatura femenina en los hogares durante el periodo intercensal 1993-2005, es un fenómeno creciente, no solo en Colombia sino en toda Latinoamérica.

De los informantes para el estudio mayores de 46 años, el $78.6 \%$ posee ocupaciones con factor de riesgo por ser mano de obra no calificada que asume esta condición por la naturaleza misma de su labor: ser conductores u operadores de maquinaria, seguido de oficios varios y mecánica (10\%), siendo más vulnerables por la edad y baja capacidad de responder frente a los riesgos ocupacionales. En Colombia, cerca del $60 \%$ de los trabajadores hace parte del sector informal y el subempleo es significativamente amplio (27).

La movilización urbana en mototaxi es un problema social por ser ésta una actividad informal que genera altos índices de accidentalidad y traumatismos en un $83 \%$, frecuentes en el último trimestre del año y a principios del año, siendo afectados los parrilleros entre los 18 y 25 años de edad (28); por lo que se implementó el Decreto 396 del 29 de Diciembre de 2014 para acabar con el mototaxismo como actividad ilegal (29).

En una encuesta aplicada en el 2014 sobre percepción ciudadana de la Red de Ciudades Cómo Vamos (30), se encontró que Valledupar es la ciudad que tiene menor satisfacción con el transporte en un $41 \%$, en donde el mototaxismo no sólo ha causado un impacto social sino también, a largo plazo, este fenómeno podría contribuir en la proliferación de lesiones pre-cancerosas (más que todo cáncer de piel), enfermedades respiratorias, problemas de columna, enfermedades relacionadas con el aparato reproductor masculino y, sobre todo, alergias y enfermedades del cuero cabelludo por usar un casco de seguridad que ha sido utilizado por muchas personas. Estos riesgos hacen vulnerable a la población, al exponer su vida e integridad debido a la aparición de patrones culturales negativos como el vandalismo,

\section{Condición de vida}

Con relación a la ausencia institucional para atender la educación, el $79.2 \%$ de los informantes 
E-ISSN 2322-7028

Vol. 13 No. 1

Ene - Jun 2016

Cúcuta, Colombia del estudio afirma que el sector oficial es el que menos cobertura ofrece en comparación con el sector privado o de organizaciones cívicas, en especial preescolar y primaria que es cubierta por grupos religiosos, concordando con el informe del Ministerio de Educación Nacional (31) en el año 2015, que reconoce que sólo el $78.5 \%$ de niñas y niños son atendidos en establecimientos públicos con programas de primera infancia o preescolar, entre $3 \mathrm{y}$ 5 años, enfatizando dicho crecimiento en el esfuerzo presentado en programas de primera infancia, cuando el Estado debe garantizar en un $100 \%$ la educación de preescolar y básica primaria.

El bajo nivel de formación académica y de formación para el trabajo explica la baja capacidad de oferta de mano de obra calificada, debido a la escasa oferta de programas de formación técnica y de educación superior en la región, hecho que ha sido manifestado por la población estudiada. Se evidencia también que cerca de la tercera parte de la población $(32,7 \%)$ en el año 2012, sigue siendo pobre, al tiempo que el país se mantiene como uno de los más desiguales de América Latina (32).

Como se dijo anteriormente, el Ministerio de Educación Nacional afirma que el nivel de la educación media en el país (grados $10^{\circ}$ y $11^{\circ}$ ) alcanza una cobertura del $41 \%$ y el retiro de los jóvenes de las aulas de clases se da en este nivel. En el estudio se aprecia que el abandono escolar se presenta paulatinamente desde el grado sexto, teniendo en cuenta que la educación media es una etapa vital para el fortalecimiento de competencias cognitivas y socioemocionales fundamentales para el desarrollo de posteriores competencias laborales, poniendo en peligro a las actuales y futuras generaciones (32-33).

La baja cobertura en educación genera en la población joven una diversidad de problemas emocionales, cimentando una cultura de violencia en respuesta a la incertidumbre, ante la ausencia de una sociedad que lidere el desarrollo económico local y que los inserte en la economía nacional e internacional, contando con un máximo nivel educativo pertinente, reconociendo que es una función importante en la determinación de los ingresos laborales y la seguridad del empleo (34).

El espacio público, como elemento estructural del sistema urbano en las ciudades, ofrece grandes oportunidades de intervención para impactar la cultura y la calidad ambiental, pero el $25 \%$ de las familias afirma que la comunidad hace uso indebido de los espacios públicos, ocupándolos y apropiándose de ellos, utilizándolos para negocios de ventas ambulantes, publicidad gráfica y grafitis con mensajes y actos de violencia que, aunado a la falta de mantenimiento y alumbrado de dichos lugares, contribuye al deterioro del entorno e impide a la población el aprovechamiento de los mismos, ante la ruptura de las relaciones sociales, las costumbres y la actividad diaria de la población.

Martel y Baires (35) se refieren a estos espacios públicos como espacios de desencuentro y de inseguridad, cuya construcción social y simbólica de barrio está profundamente matizada por la convivencia, la conversación y el juego, aunque también se construye desde la violencia, la inseguridad y los conflictos.

El $100 \%$ de los líderes reconoce que a los parques destinados a actividades deportivas y socioculturales el Estado no les hace control sanitario. Además, no se cuenta con una organización comunitaria que vele por ello, pese a que es asumido por sus moradores de acuerdo al momento de su uso.

En este sentido, en el Distrito de Cartagena se puede apreciar la inexistencia de instituciones especializadas en el manejo y administración de espacios públicos, debilidad en el cumplimiento de la normatividad existente, baja capacidad técnica de los funcionarios para la correcta toma de decisiones, falta de conciencia ciudadana sobre su uso y cuidado, invasión y ocupación indebida, falta de estandarización y claridad en procesos de diseño, aprobación y construcción del espacio, poca inversión para su generación y/o rehabilitación, falta de inventarios, falta de saneamiento de los espacios públicos y falta de una política clara que oriente la gestión de la administración distrital (36), constituyéndose en una situación similar para Valledupar.

Las desigualdades sociales, la baja solidaridad y falta de fraternidad van generando indiferencia por el otro, desconocimiento de la labor de las juntas de acción comunal, diversas formas de violencia y enfermedades sociales como la prostitución y drogadicción, las cuales van arraigando la cultura de la violencia e indiferencia, en donde la mayor parte del mundo académico no sensibiliza o no comprende 
el fuerte vínculo que existe entre las condiciones de vida, la salud y el desarrollo.

La no recolección de las basuras y la ausencia de un sistema de alcantarillado convierten el ambiente en antihigiénico, no propicio para habitarlo y fuente de enfermedades infecciosas (37). Además, el uso de gas propano y una vivienda en calidad de arrendamiento generan una situación de riesgo por las mismas condiciones de su mantenimiento y su localización dentro de la misma habitación.

El problema de los asentamientos por desplazamiento trae consecuencias en la vida cotidiana tanto a los desplazados como a los moradores, debido al cruce de culturas, de expectativas de vida, de desigualdades e inequidades, todo lo cual potencia el hacinamiento en las viviendas en un $15 \%$, con las consecuencias que se pueden derivar para la salud familiar y pública, por ser un determinante social para la salud (20).

\section{Cuidado de la salud}

En las mujeres gestantes se aprecia falta de responsabilidad y sensibilidad acerca de la importancia del programa de promoción y prevención, para vigilar la evolución del proceso de gestación e identificar precozmente factores de riesgo biopsicosocial, enfermedades asociadas y propias del embarazo $\mathrm{y}$ asegurar un manejo adecuado y oportuno que disminuya la morbimortalidad materna y perinatal, que hoy por hoy constituye el principal indicador de nivel de desarrollo de un país (38). Un embarazo a temprana edad es considerado de alto riesgo de morbilidad por el bajo peso al nacer, la prematurez y mortalidad materna, perinatal e infantil (39).

La población que no utiliza algún método anticonceptivo se convierte en un factor de riesgo para el aumento de la tasa de natalidad y la incidencia de algunas enfermedades de transmisión sexual, más aún cuando se continúa con la exclusión del hombre en los programas de planificación familiar, convirtiéndose de esta manera en un riesgo trazador por las condiciones culturales y de género. Según la Organización Panamericana de la Salud (40), el uso de métodos modernos de planificación familiar por parte de las mujeres aumentó de $68,2 \%$ en 2005 a $72,9 \%$ en 2010; la esterilización femenina fue el método más usado, seguido por los anticonceptivos inyectables.
La edad es un factor de riesgo para la aparición de enfermedades, como consecuencia del deterioro que presenta el organismo por el paso del tiempo que, unido a los estilos de vida, la ocupación y las implicaciones de la pobreza, van influyendo de manera determinante en la salud de los individuos (41).

Los problemas de salud también se vinculan con el mal uso o abuso de los medicamentos. La ingesta de fármacos desconociendo su efecto y composición puede traer problemas a la salud, desde una simple intolerancia por alergia hasta potenciar o anular efectos de otro medicamento que el paciente esté tomando. De otro lado, el número de veces que las familias consultan en búsqueda de solución a un padecimiento de salud específico, podría ser la causa de la automedicación, el uso de medicina natural o la combinación de esta con terapia farmacológica, en procura de un bienestar.

Se resalta la influencia que tiene el programa de crecimiento y desarrollo en el componente de vacunación como factor protector para la salud; información que muestra una cobertura útil con base en el alto porcentaje de cumplimiento del esquema de vacunación en los recién nacidos informados, de acuerdo con lo dispuesto en la guía de protección específica. Sin embargo, el $2.3 \%$ que no ostenta esta condición de vacunación completa está relacionada con haber tenido un parto domiciliario o que no fue realizado en instituciones prestadoras de servicios de salud. La vacunación es la mejor estrategia costoefectiva demostrada universalmente para la reducción de la incidencia y mortalidad por las enfermedades inmuno prevenibles (42).

Se observa, en las familias participantes, que las madres no se acogen a los beneficios de la lactancia materna a pesar de la existencia de la política pública estatal en la prevención de enfermedades prevalentes de la infancia, desarrollando programas de fomento a la lactancia materna como mínimo hasta los 6 meses y como único alimento, fortalecimiento del vínculo afectivo madre e hijo y la promoción del desarrollo saludable de los infantes (43).

La edad constituye, para la población masculina mayor, un factor de riesgo de desarrollar cáncer de próstata, razón por la cual la realización del examen resulta fundamental para el diagnóstico oportuno del

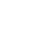


mismo. En un estudio (44) realizado en el Municipio de Juiz de Fora, Brasil, se encontró que el 54,4\% de los participantes ya se había realizado el examen de próstata motivado por una rutina de prevención, referida por el $61,6 \%$ de los entrevistados. Sin embargo, poco más de la mitad se realizó el examen hacía menos de un año $(58,8 \%)$. En cuanto a la realización del antígeno prostático específico (PSA), un $51,9 \%$ afirmó ya haberla realizado y un $65,5 \%$ manifestó haber hecho este examen hacía menos de un año.

Una visión general del ocio, concebido como una forma de utilizar el tiempo libre (aquel que no está dedicado ni al trabajo ni a otras obligaciones biológicas, familiares o sociales), mediante una libre elección que resulte gratificante al individuo y sea vivida con dinamismo y de forma crítica (45), encontró, con respecto al tiempo de ocio de las familias de la Comuna Tres, que menos de la cuarta parte de su población lo invierte en actividades deportivas -práctica sumamente beneficiosa para la salud tanto física como mental, así como un medio para forjar el carácter, la disciplina, la toma de decisiones y el cumplimiento de las reglas, beneficiando así el desenvolvimiento de quien las practica en todos los ámbitos de la vida cotidiana-.

\section{Condiciones higiénico sanitarias de expendios}

La correcta aplicación de las condiciones sanitarias ofrece al consumidor una sensación de seguridad y confianza para adquirir un producto, siempre y cuando los manipuladores también cumplan con buenas prácticas de higiene en el manejo de los alimentos y condiciones higiénicas básicas ideales en el personal manipulador establecidas en el Decreto 3075 de 1997 (14). Se pudo observar que el 22.5 $\%$ de los manipuladores de expendios de alimentos ubicados especialmente en los estratos tres y uno no cumplen con las normas de higiene al no acoger los parámetros de limpieza e higiene personal, no aplicar buenas prácticas higiénicas en sus labores ni lavarse las manos con agua y jabón antes de comenzar su trabajo y después de manipular cualquier material u objeto. Igualmente, el $18.5 \%$ de los expendedores no garantiza la conservación y protección de los productos, constituyéndose en un factor de riesgo para adquirir enfermedades, en especial aquellas que son trasmitidas por alimentos.
Desde que el hombre, con el fin de satisfacer sus necesidades básicas, comenzó a interactuar con su entorno, desencadenó un proceso de transformaciones que ha hecho posible el desarrollo ascendente de la humanidad (46). Sin embargo, ante las adversidades económicas, estas comunidades han generado condiciones negativas en la salud por cuanto no cumplen con lo normatizado en el Decreto 3075 de 1997 (14).

\section{CONCLUSIONES}

Los ingresos de la población estudiada provienen, en su mayoría, del desempeño en trabajos informales (rebusque) para la subsistencia y la satisfacción de las necesidades básicas, impidiendo el acceso pleno a la educación básica media y superior. Esta población se ocupa como mano de obra no calificada y se observa presencia de menores de edad trabajadores.

La responsabilidad que se asigna a las mujeres sobre la mayor parte del trabajo doméstico y el cuidado de la familia genera desigualdad de oportunidades. La falta de autonomía en la capacidad de generación de ingresos de las mujeres las vuelve especialmente vulnerables, particularmente en determinadas etapas de su ciclo vital, tales como embarazo, lactancia, cuidado de niños pequeños y vejez.

En las condiciones de vida de la Comuna Tres de la ciudad de Valledupar se encontró la ausencia de instituciones que promuevan la ocupación del tiempo libre y el ocio en la comunidad; los habitantes toman como tiempo de ocio la religión.

Los riesgos en el autocuidado, encontrados en mayor proporción en cuanto al cuidado primario, están relacionados con el periodo de la lactancia materna e inicio de la alimentación complementaria, seguidos de la atención primaria que debe ofrecerse a los hijos y adultos mayores para prevenir infecciones gastrointestinales que están muy relacionadas con los estilos y modos de vida, recurriendo a la automedicación o medicina natural mal concebida o utilizada, atención primaria ante problemas visuales, neurológicas o aquellos relacionados con el ciclo vital humano como las cardiovasculares.

En el cuidado doméstico, las personas conviven con animales domésticos sin responsabilidad frente a su cuidado, con falta de valores ciudadanos que se 
perciben en la ausencia de control sanitario de las deposiciones a campo abierto y la falta de vacunas para la prevención de la rabia o accidentes por mordedura. Igualmente, también relacionado con la cultura ciudadana, se encuentra el desconocimiento del valor de los beneficios del trabajo colectivo ante problemas sociales compartidos, como lo es el riesgo de cortocircuitos en el hogar, que pueden ocasionar incendios, atentados contra la vida misma del individuo y de la comunidad.

El mayor riesgo relativo para la salud, en sí mismo, se encuentra en la pobreza, por cuanto ella genera en la comunidad modos de vida que afectan a los demás en la medida en que se busca cómo generar ingresos para el sustento; aquí, las deficientes prácticas higiénico sanitarias observadas en los diversos tipos de expendios de alimentos están alentando en gran escala la salud de sus consumidores, sin un control del Estado.

Se aprecia la falta de institucionalidad, ya sea por ausencia de infraestructura o por la baja proyección a través de programas de educación que apunten hacia la consecución de estilos y modos de vida saludables, fomentando el ejercicio físico en la población, y la convivencia pacífica, como parte de un desarrollo humano y sostenible.

Se evidencia cómo las acciones del ser humano en la convivencia y en el cuidado del entorno han generado modos de vida deficientes. La intervención humana en el ambiente ha producido daños ecológicos.

\section{CONFLICTO DE INTERESES}

Los autores declaran no tener ningún conflicto de intereses.
E-ISSN 2322-7028

Vol. 13 No. 1

Ene - Jun 2016

Cúcuta, Colombia 


\section{REFERENCIAS BIBLIOGRÁFICAS}

1. Schütz GE, Da Silva MG, Ribeiro MA, De Magalhães V. Sobre determinação sócia ecológica da saúde da ruralidade em Humaitá, AM, Brasil. Ciênc. saúde coletiva [Internet]. 2014 [consultado 25 de noviembre de 2014]; 19(10): 4051-4059. Disponible en: http://dx.doi.org/10.1590/1413-812320141910.09392014

2. Páez M, Castaño J. Estilos de vida y salud en estudiantes de una facultad de psicología. Psicología desde el Caribe [Internet]. 2010 [consultado 27 de octubre 2013]; 25:155-176. Disponible en: http://www.scielo.org.co/ scielo.php?script=sci arttext\&pid=S0123-417X2010000100008

3. Cabrera VE, Salazar PA, Docal MC, Aya VL, Ardila MM, Rivera R. Estilo de vida de los jóvenes y las necesidades de educación sexual. [Internet]. Bogotá DC.: Procuraduría General de la Nación, Instituto de Estudios del Ministerio Público IEMP Ediciones; 2013 [consultado 29 de octubre de 2013]. Disponible en: http:// www.mineducacion.gov.co/cvn/1665/articles-340716_archivo_pdf.pdf

4. Vidal D, Chamblas I, Zavala M, Müller R, Rodríguez Mc, Chávez A. Determinantes sociales en salud y estilos de vida en población adulta de Concepción, Chile. Cienc. Enferm. [Internet]. 2014 [consultado 27 de diciembre de 2014];20(1):61-74. Disponible en: http://dx.doi.org/10.4067/S0717-95532014000100006

5. Echemendía B. Definiciones acerca del riesgo y sus implicaciones. Revista Cubana Hig Epidemiol [Internet]. 2011 [consultado 27 de diciembre 2013]; 49(3): 470-481. Disponible en: http://scielo.sld.cu/scielo.php?script=sci arttext\&pid $=$ S1561-30032011000300014\&lng=es.

6. Braveman P, Gottlieb L. The Social Determinants of Health: It's Time to Consider the Causes of the Causes. Nursing in 3D: Diversity, Disparities, and Social Determinants. Public Health Reports [Internet]. 2014 [consultado 2 de febrero de 2015]; 129(Supl2):19-31. Disponible en: http://www.publichealthreports.org/ issueopen.cfm?articleID $=3078$

7. Programa de las Naciones Unidas para el Desarrollo (PNUD), Interconexión Eléctrica (ISA). Alcaldía de Valledupar, Fundación Universitaria del Área Andina. Valledupar 2012.Estado de avance de los Objetivos de Desarrollo del Milenio. [Internet]. Valledupar: PNUD; 2012 [consultado 23 de agosto de 2013]. Disponible en: http://www.valledupar-cesar.gov.co/apc-aa-files/c7b1248bfd889617434791939df2ed2a/libro-valledupar estado-de-avance-de-los-objetivos-de_1.pdf

8. Alcaldía Municipal de Valledupar. Plan Desarrollo Valledupar 2012 - 2015. Hacia la transformación de Valledupar. [Internet]. Valledupar: Alcaldía Municipal; 2012 [consultado 3 de septiembre de 2014]. Disponible en:http://carbonn.org/uploads/tx_carbonndata/Plan\%20Desarrollo\%20Valledupar\%202012\%20-\%202015.pdf

9. Asociación Colombiana de Universidades (ASCUN). El pensamiento universitario No. 21. Documentos Responsabilidad social universitaria. [Internet]. Bogotá D.C.; Editorial Kimpres Ltda.; 2011 [consultado 5 de octubre de 2013]. Disponible en: http://www.cna.gov.co/1741/articles-311056_ResponsabilidadSocial.pdf

10. Sánchez-Sanabria M. La Diversidad Cultural en la formación de enfermeros. Valledupar: Ediciones UNICESAR; 2009.

11. Oliva- Gómez E. Hacia un concepto interdisciplinario de la familia en la globalización. Justicia Juris. [Internet]. 2014 [consultado 23 enero de 2016]; 10(1): 11-20. Disponible en http://www.scielo.org.co/pdf/jusju/v10n1/ v10n1a02.pdf

12. Hernández R, Fernández C, Baptista MP. Metodología de la investigación. $5^{a}$ ed. México: McGrawHill; 2010.

13. Gil F. Manejos espaciales, construcción de paisajes y legitimación territorial: En torno al concepto de monumento. Madrid: Editorial Complutum; 2003.

14. República de Colombia. Instituto Nacional de Vigilancia de Medicamentos y Alimentos (INVIMA). Buenas Práctica de manufactura Decreto 3075 de 1997. SlideShare.com [Internet]. 2013 [consultado 31 de marzo 2013]. Disponible en: http://es.slideshare.net/webmasterconfecamaras/buenas-prcticas-de-manufactura-decreto-3075de-1997

15. Ritchey J. Estadística para las Ciencias Sociales. México: Editorial McGraw-Hill; 2003.

16. Castañeda MB, Cabrera AF, Navarro Y, Vries W. Procesamiento de datos y análisis estadísticos utilizando SPSS. Porto Alegre: EDIPUCRS; 2010.

17. Senior A, Colina J, Marín F, Perozo B. Visión complementaria entre los métodos cualitativos y cuantitativos en la investigación social. Una aproximación teórica. Multiciencias 2012; 2:106-114.

18. República de Colombia. Ministerio de Salud. Resolución 08430 de 1993, octubre 4, por la cual se establecen las normas científicas, técnicas y administrativas para la investigación en salud. [Internet].Santafé de Bogotá D.C.: Ministerio de Salud; 1993 [consultado 17 de septiembre de 2013]. Disponible en: https://www.unisabana.edu.co/ fileadmin/Documentos/Investigacion/comite_de_etica/Res_8430_1993_-_Salud.pdf

19. Scribd selects books.com. Trabajo final de materiales. Chacacan. [Internet]. 2012. [consultado 3 de diciembre de 
2015]. Disponible en: http://es.scribd.com/doc/125892875/Laminas-de-Zinc-Acerolit-y-Asbesto\#scribd

20. Organización Mundial de la Salud (OMS). Declaración Política de Río sobre los Determinantes Sociales de la Salud. En: OMS. World Conference on Social Determinants of Health. [Internet]. 2011 [consultado 7 de agosto de 2015]. Disponible en: http://www.who.int/sdhconference/declaration/Rio_political_declaration_Spanish.pdf

21. Sánchez SM, Hernández SN, Galindo OJ, Romero DA, Lozano GL, Vence DN, et al. Responsabilidad Social Universitaria para el cuidado de la salud de los habitantes área urbana de Valledupar. Universidad Popular del Cesar. Valledupar: Ediciones UNICESAR; 2015.

22. Canal M, Gutiérrez R, Trujillo D, Wills E. Incidencia en el empoderamiento a comunidades atendidas por Organizaciones de Desarrollo y Paz en Colombia. Perspectivas. Análisis de temas críticos para el desarrollo sostenible. [Internet]. 2007 [consultado el 25 de septiembre del 2015]; 5(1):25-62. Disponible en http:/www.caf.com/ media/3849/PerspectivasVol5N\%C2\%BA1.pdf

23. República de Colombia, Ministerio de Educación Nacional. Reflexión estratégica sobre la educación media en Colombia. Centro Virtual de Noticias de la Educación. [Internet]. Bogotá D.C.: Mineducación; 2012 [consultado 26 de octubre de 2013]. Disponible en: http://www.mineducacion.gov.co/cvn/1665/w3-article-313357.html

24. United Nations (ONU). Transforming our world: the 2030 agenda for sustainable development. [Internet]. 2015 [consultado 2 de noviembre de 2015]. Disponible en: https://sustainabledevelopment.un.org/post2015/transformingourworld

25. Encuesta Nacional de Demografía y Salud - ENDS 2010. Asociación Probienestar de la Familia Colombiana (PROFAMILIA). Situación de las mujeres en Colombia 2010. [Internet]. Bogotá D.C.: PROFAMILIA; 2011 [consultado 15 de octubre de 2013]. Disponible en: https://hsprogram.com/pubs/pdf/FR246/FR246.pdf

26. Velásquez SP. Ser mujer jefa cabeza de hogar en Colombia. Revista de la Información Básica Revista Virtual. [Internet]. 2006 [consultado 19 de octubre de 2014]; 4(2). Disponible en: http://www.dane.gov.co/revista_ib/ html_r8/articulo4.html

27. Colombia. Consejo Privado de Competitividad. Informe Nacional de Competitividad 2009-2010. [Internet]. 2009 [consultado 15 de marzo de 2014]. Disponible en: http://www.compite.com.co/site/informe-nacional-decompetitividad-2009-2010-2/

28. Peñaloza RE, Ortegón JS, Flórez CF, Patiño C, Cuenca MP, Rodríguez JM, et al. Caracterización e identificación de factores de riesgo asociados a lesiones causadas por el tránsito para el diseño de intervenciones efectivas en dos ciudades de Colombia. Pontificia Universidad Javeriana. Centro de Proyectos para el Desarrollo (Cendex) [Internet]. Colombia, Cendex, PUJ; 2012 [consultado 16 de agosto de 2014]; Disponible en: http://cendex.javeriana.edu.co/documents/2202501/2364965/LCT+Foro+Ibague/65995551-514b-4014-ac66-e03f33b13e7c

29. Alcaldía Municipal de Valledupar. Informe de Gestión Vigencia 2014. [Internet]. Valledupar: Alcaldía Municipal; 2014 [consultado 8 de febrero de 2015]. Disponible en: http://valledupar-cesar.gov.co/apc-aa-files/31396630306165386361653361363937/informe-de-gestion-vigencia-2014.pdf

30. Jaramillo MC. Movilidad en las ciudades de la 9 red cómo vamos. En: Informe de calidad de vida. [Internet]. 2014 [consultado 29 de noviembre del 2014]. Disponible en: redcomovamos.org/wp-content/uploads/2015/03/ Movilidad_ICV7.pdf

31. República de Colombia, Ministerio de Educación Nacional. Informe de Revisión Nacional de Educación para Todos (EPT) 2015. [Internet]. Bogotá D.C.: Mineducación; 2014 [consultado 22 de agosto de 2015]. Disponible en: http://unesdoc.unesco.org/images/0023/002300/230024S.pdf

32. Delgado BM. La educación básica y media en Colombia: retos en equidad y calidad. Bogotá D.C.: Fedesarro1lo. [Internet]. 2014 [consultado 28 de noviembre de 2014]. Disponible en: http://www.fedesarrollo.org.co/ wp-content/uploads/2011/08/La-educaci\%C3\%B3n-b\%C3\%A1 sica-y-media-en-Colombia-retos-en-equidad-ycalidad-KAS.pdf

33. Organización de las Naciones Unidas para el Desarrollo de la Ciencia y la Cultura (UNESCO). Marco de Acción Educación 2030. Hacia una educación de calidad, inclusiva y equitativa y un aprendizaje a lo largo de la vida para todos. En: Foro Mundial sobre la Educación [Internet]. Corea; 2015 [consultado 20 de diciembre de 2015]. Disponible en: http://unesdoc.unesco.org/images/0023/002332/233245s.pdf

34. Organización Panamericana de la salud (OPS), Organización Mundial de la Salud (OMS). Capítulo 2: Determinantes e inequidades en salud. Salud en las Américas. [Internet]. 2012 [consultado 23 de octubre de 2013]. Disponible en: http://www.paho.org/SaludenlasAmericas/index.php?option=com_content\&view=article\&id=58 $\% 3$ Ahealth-determinants-and-inequalities\&catid $=24 \% 3$ Achapters\&Itemid $=55 \&$ lang $=$ es

35. Martel R, Baires S. Imaginarios del miedo y geografías de la inseguridad: construcción social y simbólica del espacio público en San Salvador. En: Lindón-Villoria A, Hiernaux ND, Aguilar MA. (Coords.) Lugares e imaginarios en la metrópolis. Barcelona: Antropos Editorial, Universidad Autónoma Metropolitana; 2006. p. 119-135. 
36. Villarreal H, Doria A. Cartagena de Indias: Indicadores de espacio público [Internet]. Cartagena de Indias: Alcaldía Mayor de Cartagena de Indias; 2011 [consultado 22 de junio de 2014]. Disponible en: http://hdl.handle. net/10819/368

37. Vélez H, Rojas W, Borrero J, Restrepo J. Enfermedades Infecciosas. Fundamentos de Medicina. $6^{\text {a }}$ ed. Medellín: Corporación para Investigaciones Biológicas; 2003.

38. República de Colombia. Departamento Nacional de Planeación. Bases del Plan Nacional de Desarrollo 20142018. Versión para el Congreso. [Internet]. Bogotá D.C.: Oficina Asesora de Comunicaciones; 2014 [consultado 19 de noviembre de 2014]. Disponible en http://portal.dafp.gov.co/portal/pls/portal/formularios.retrive publicaciones?no $=2421$

39. Cluet I, Rossell MR, Álvarez T, Rojas L. Factores de riesgo asociados a la prematuridad en recién nacidos de madres adolescentes. Rev Obstet Ginecol Venez 2013; 73 (3):157-170.

40. Organización Panamericana de Salud (OPS), Organización Mundial de la Salud (OMS). Salud en las Américas. [Internet]. Colombia: OPS; 2012 [consultado 23 de febrero de 2014]. Disponible en: http://www.paho.org/ SaludenlasAmericas/index.php?option $=$ com_content\&view $=$ article \&id $=30 \% 3$ Acolombia\&catid $=21 \% 3$ Acount ry-chapters\&Itemid $=30 \&$ lang $=$ es

41. Ostchega Y, Paulose-Ram R, Dillon CF, Gu Q, Hughes JP. Prevalence of peripheral arterial disease and risk factors in persons aged 60 and older: data from the National Health and Nutrition Examination Survey 1999-2004. J Am Geriatr Soc. 2007;55:583-9.

42. República de Colombia, Ministerio de la Protección Social. Lineamientos para la gestión y administración del programa ampliado de inmunizaciones - PAI 2015. [Internet]. Bogotá D.C.: Minsalud; 2015 [consultado 18 de diciembre de 2015]. Disponible en: https://www.minsalud.gov.co/sites/rid/Lists/BibliotecaDigital/RIDE/VS/PP/ PAI/lineamientos-pai-2015.pdf

43. República de Colombia, Ministerio de la Protección Social. Acción Social, Fondo para la Infancia de las Naciones Unidas (UNICEF), Programa Mundial de Alimentos de las Naciones Unidas (PMA). Plan Decenal de Lactancia Materna 2010-2020. [Internet]. Bogotá D.C.: Minprotección; 2010 [consultado 23 de octubre de 2015]. Disponible en: http://www.huila.gov.co/index.php?option $=$ com_content\&view $=$ article\&catid $=350 \% 3 \mathrm{~A}$ nutri cion\&id $=68069 \% 3$ Aplan-nacional-de-lactancia-materna-\&Itemid $=3706$

44. Pereira E, Motta MC, Salvador MC, Harter R. Barreras en relación a los exámenes de rastreo del cáncer de próstata. Rev. Latino-Am. Enfermagem [Internet]. 2011 [consultado 24 de febrero de 2014]; 19[1]:73-80. Disponible en: http://www.scielo.br/scielo.php?script=sci_arttext\&pid=S0104-11692011000100011\&lng=en. http:// dx.doi.org/10.1590/S0104-11692011000100011

45. Hernández A, Morales V. Una revisión teórica: ocio, tiempo libre y animación sociocultural.2015. Efdeportes. com Revista Virtual. [Internet]. 2008 [consultado 12 de septiembre 2015];13(127). Disponible en: http://www. efdeportes.com/efd127/una-revision-teorica-ocio-tiempo-libre-y-animacion-sociocultural.htm

46. Mathus-Robles MA. Principales aportaciones teóricas sobre la pobreza. Revista Contribuciones a las Ciencias Sociales. Eumed.net [Internet]. 2008 [consultado 2 de noviembre de 2014]. Disponible en: http://www.eumed. net/rev/cccss/02/mamr.htm 